\title{
A convivência em família com o portador de transtorno psíquico
}

\section{Familiar living with a psychically perturbed person}

\section{La convivencia en la familia con el portador de transtorno psíquico}

\author{
Maiquel Danzer de Souza', Luciane Prado Kantorski", Eda Schwartz"I" \\ Sueli Aparecida Frari Galeralv, Sidnei Teixeira Júnior ${ }^{\vee}$
}

\footnotetext{
Enfermeiro formado pela Faculdade de Enfermagem e Obstetrícia da Universidade Federal de Pelotas. E-mail: kantorski@uol.com.br.

"Professora Adjunta da Faculdade de Enfermagem e Obstetrícia da Universidade Federal de Pelotas. Doutora em Enfermagem. Apoio CNPq

III Professora Adjunta da Faculdade de Enfermagem e Obstetrícia da Universidade Federal de Pelotas. Doutora em Enfermagem.

IV Professora Doutora da Escola de Enfermagem de Ribeirão Preto da Universidade de São Paulo.

${ }^{\vee}$ Enfermeiro. Mestrando do Programa de Pós-Graduação em Enfermagem da Universidade Federal do Rio Grande do Sul.
}

\section{RESUMO}

Este estudo teve como objetivo conhecer as experiências da família no convívio com o portador de transtorno psíquico, utilizando-se da avaliação estrutural deste grupo familiar. Consiste num estudo descritivo de abordagem qualitativo. Os dados foram coletados, em 2004, a partir de uma família que possui um de seus membros portador de transtorno psíquico e vem sendo acompanhada num Centro de Atenção Psicossocial. Tais dados foram obtidos por meio de três entrevistas realizadas no domicílio, seguindo-se a orientação teóricometodológica do Modelo Calgary de Avaliação de Família, num recorte centrado na avaliação estrutural. Os resultados foram apresentados enfatizando-se os seguintes aspectos: estrutura interna (composição familiar, gênero, orientação sexual, ordem de nascimento, subsistemas, limites), estrutura externa (família extensa e sistemas mais amplos), o contexto (etnia, raça, classe social, religião e espiritualidade, ambiente). Consideramos que o modelo utilizado consiste num aporte relevante para avaliação de famílias com portadores de transtorno psíquico, apontando para aspectos centrais do cuidado de enfermagem a estas famílias.

Descritores: Família; Enfermagem; Saúde mental.

\section{ABSTRACT}

This paper aimed to evaluate the structure of the family where the bearer of mental disturb upset lives and he got sick. This qualitative and descriptive study. This data were collected and 2004, from a family in which one member is psychically perturbed, and that family has been followed up in a Center for Psycosocial Care. Such data were obtained from three home interviews following the theoretical methodological guidance of Calgary's Method for Family Evaluation, in a cutting based in a structural evaluation. The results shown emphasized the following aspects: internal structure (familiar constitution, gender, sexual direction, birthday order, subsystems, limits), external structure (long family and larger systems), context (ethnics, race, social level, religion and spirituality, environment). We consider the model used is a relevant aport to evaluating families living with psychically perturbed people, pointing out the core aspects of the nursing care for those families.

Descriptors: Family; Nursing; Mental health.

\section{RESUMEN}

Este estudio tenido como el objetivo evaluar la estructura de la familia dónde el portador de transtorno mental seria perturbó las vidas y él se enfermó. Estudio descriptivo y cualitativo. Los datos eran recolectados en 2004, el arranque reunido de una familia que posee uno de su portador de los miembros de transtorno psíquico y se ha acompañado en un Centro de Atenção Psicossocial. Se obtuvieron los datos a través de tres entrevistas logradas en la casa, siguiéndose la orientación teórico-metodológica del Modelo Calgary de Evaluación de Familia, en una corte centrada en la evaluación estructural. Los resultados fueron presentados que el ser dio énfasis a los aspectos siguientes: internos de la estructura (la composición familiar, el género, la orientación sexual, pide del nacimiento, el subsistemas, los límites), la estructura externa (la familia extensa y los sistemas más anchos), el contexto (la etnia, la raza, clase social, la religión y espiritualidad, lo ambiente). Nosotros consideramos que el modelo usado consiste en una contribución pertinente para la evaluación de familias con portadores de transtorno psíquico, evidenciando os aspectos centrales del cuidado de enfermeria para las familias.

Descriptors: Familia; Enfermería; Salud mental. 


\section{NTRODUÇÃO}

A família se constitui na base da sociedade. No grupo familiar experimentamos sentimentos e vivências em cuidar do outro, o que se exacerba ainda mais quando temos alguém em nossa família com um problema de saúde.

Existem diferentes tipos de configurações familiares que são classificadas $\operatorname{como}^{(1)}$ : Nuclear também chamada de Biparental: composta por pai, mãe e filhos. Nesta se destacam as funções: social, política, sexual, econômica, reprodutiva e educativa; Extensa ou Ramificada: onde estão incluídas em diferentes gerações na mesma família; Associativa: quando incluídos entre os membros, estão também as pessoas com as quais são mantidos estreitos laços afetivos; Adotiva: atribuímos essa denominação ao conjunto de pessoas que ao se encontrarem, desenvolvem afinidade, passam a conviver considerando-se uma mesma família, independente de qualquer consangüinidade; Dual ou Monoparental: aqui denominada como aquela formada apenas por dois membros (mãe-filho, pai-filho, esposo-esposa, companheiro-companheira); Ampliada: forma-se sem a necessidade de haver espaço físico comum, nem de serem desempenhadas todas as funções tradicionais em conjunto; Recomposta: aquela família (marido, esposa e filhos ou dois cônjuges e filhos), que após uma primeira experiência não bem sucedida, faz uma nova tentativa com o mesmo ou com outro cônjuge; Homossexual: resulta da união de pessoas do mesmo sexo. É uma prática que começa a se difundir na atual sociedade pós-moderna.

Por isso é interessante utilizar o conceito de família como um sistema, pois este conceito possibilita incluir todos os tipos listados acima. A família brasileira é, ainda predominantemente, nuclear ${ }^{(1)}$, isto é, cada uma se reproduzindo e definindo papéis e tarefas, para cumprimento pelos seus membros, a partir dos padrões intrafamiliares, levando em conta, também, os da região em que vive.

Em toda família coexistem tendências para saúde e para doença, o diferencial se fará a depender de como a família enfrenta situações de crise, de como está à afetividade e a comunicação entre seus componentes. Estes serão indicadores de relações saudáveis ou adoecidas ${ }^{(2)}$. "O adoecimento de um membro na família representa, em geral, um grande abalo. A gravidade e a longa duração dos sintomas, os fracassos sociais dos pacientes, as dificuldades de comunicação e interação, produzem frustração e desespero e são um convite para um progressivo isolamento da vida comunitária"(2).

Em nosso país é assustador o número de pessoas que atualmente sofrem de algum tipo de transtorno psíquico. A crise financeira que há muito o Brasil vem enfrentando é um forte fator para o aumento dos casos ligados a psiquiatria, não podendo esquecer que a violência também tem uma participação significativa no aumento destes números. Conseqüentemente, muitas famílias possuem um familiar com transtorno psíquico e dependem do Estado para ajudar a custear o tratamento. Muitas vezes, o familiar de um portador de um transtorno psíquico deixa de trabalhar para cuidar o ente-querido, tendo assim, maior dificuldade financeira.

Historicamente, as políticas públicas de saúde mental têm se constituído de modo que o Estado passa a assumir um papel decisivo na reestruturação da atenção psiquiátrica. Em 1987, no Brasil com a 1a Conferência Nacional de Saúde Mental e em seguida com a Declaração de Caracas, na Venezuela redigida em 1990, os países latino-americanos reforçam a ênfase para a promoção de modelos substitutivos concentrados na comunidade e integrados com suas redes sociais, preponderando a manutenção do doente em seu meio social ${ }^{(3)}$.

Tal idéia tem dupla repercussão: por um lado, o hospital psiquiátrico deixa de ser o componente central da atenção psiquiátrica e, por outro, propõe que os serviços comunitários passem a ser o principal meio para se obter atendimento.

O tratamento e a instituição do cuidado deixam de significar apenas a prescrição de medicamentos, a aplicação de terapias, para tornar-se um ocupar-se do cotidiano, do tempo, do espaço, do trabalho, do lazer, do ócio, do prazer, do sair, da organização de uma atividade conjunta quando o foco do cuidado se desloca da doença para o sujeito em sofrimento ${ }^{(4)}$.

Esta organização envolve construir uma nova forma de cuidado que, não seja mais de exclusão e isolamento, mas, pautada, sobretudo, na democracia, solidariedade e tolerância em relação à diferença. Uma forma de cuidado que se revele numa atitude de colocar atenção, mostrar interesse, compartilhar e estar com o outro com prazer; não numa atitude de sujeito-objeto, mas de sujeito-sujeito, numa relação não de domínio sobre, mas de convivência, não de intervenção, mas de interação ${ }^{(5)}$.

Esta nova forma de cuidar, em que o vínculo aparece como possibilidade de construção de caminhos menos estigmatizantes, implica na interação do serviço e seus profissionais com a família do portador de transtorno psíquico ${ }^{(6)}$.

Os papéis assumidos pelos membros da família mantêm relação com o que consideram fonte de estresse ou de apoio. A identificação dos papéis desempenhados, das fontes de apoio e das redes sociais consiste em fatores essenciais para planejar as intervenções de enfermagem ${ }^{(7)}$.

O questionamento inicial para o desenvolvimento desse trabalho consiste no fato de a família ter uma participação mais efetiva no acompanhamento do indivíduo em sofrimento psíquico, pois é possível 
observar que há diferentes formas de a família perceber e conviver com essa pessoa como evidenciado em estudos anteriores ${ }^{(8)}$.

Em vista disto propomos desenvolver uma investigação que tem como objetivo avaliar estruturalmente a família onde o portador de transtorno mental grave vive e adoeceu.

\section{METODOLOGI A}

Estudo descritivo de abordagem qualitativa, pois se aprofundou no mundo dos significados das ações e relações humanas, um lado não perceptível e não captável em equações, medidas e estatísticas. O foco desse tipo de estudo é com um nível de realidade que não pode ser quantificado, pois trabalha com o universo de significados, motivos, aspirações, crenças, valores e atitudes relacionadas a esta temática $^{(9)}$.

A investigação foi realizada num CAPS (Centro de Atenção Psicossocial) situado em uma cidade na região sul do estado do Rio Grande do Sul, bem como no domicílio dos familiares do portador de transtorno psíquico. Para sua realização foi selecionada uma família de um portador de transtorno psíquico em tratamento no CAPS, no ano de 2004. Os critérios para seleção desta foram: ser familiar de portador de transtorno psíquico, que manifestasse interesse em participar do tratamento e inserção nas atividades do CAPS há mais de um ano, tais como: atendimento individual e/ou grupal a portadores de transtorno psíquico e familiar.

Foram respeitados os princípios éticos previstos na Resolução do Conselho Nacional de Saúde no 196/1996 da legislação brasileira que regulamenta a pesquisa em seres humanos, tendo sido aprovado no Comitê de Ética da Faculdade de Medicina da Universidade Federal de Pelotas, ofício 043/2004. Os familiares que aceitaram participar da pesquisa receberam um termo de consentimento livre esclarecido, no qual foi garantido o anonimato e o sigilo das informações, bem como a liberdade de desistir do estudo no momento que desejassem. A coleta de dados foi realizada através da aplicação de uma entrevista aberta, na qual foram solicitadas informações dos familiares que permitiram compor o genograma e o ecomapa, tendo duração de dois meses.

O genograma e o ecomapa são instrumentos que auxiliam a avaliação estrutural da família. Ambos são simples de serem utilizados. Eles permitem uma rápida visão da complexidade das relações familiares e funcionam como uma rica fonte de informação, de forma sucinta, para planejamento de estratégias ${ }^{(10)}$.

O genograma é um desenho ou diagrama da árvore familiar que agrega informações sobre os membros da família e seus relacionamentos nas três últimas gerações. O ecomapa, por sua vez, é uma representação das relações da família com o supra- sistema (pessoas significativas, instituições do contexto da família). Ele nos permite uma "fotografia" entre as principais relações entre a família e o mundo ${ }^{(10)}$.

Estes instrumentos começaram a serem preenchidos na entrevista inicial, sendo modificados ou complementados nas seguintes. Os membros da família participaram ativamente na elaboração. Iniciou-se o preenchimento do genograma pelas pessoas que estavam dando as informações (no caso, a mãe e o portador de transtorno psíquico). Estes instrumentos foram usados para conhecer as experiências da família, identificando elementos do contexto da vida familiar que determinaram diferentes atitudes frente ao indivíduo portador de transtorno psíquico.

A identificação dos sujeitos do estudo foi realizada através de nomes fictícios, quais sejam: para o portador de transtorno psíquico, Guilherme; para o irmão que mora junto, Ronaldo; para o pai, Miguel; para a mãe, Isabel; para os demais, foram utilizados apenas os termos cotidianos como o irmão mais velho, a irmã, o cunhado, a ex-cunhada, entre outros.

\section{RESULTADOS E DISCUSSÃO}

Neste espaço apresentamos os dados obtidos nas entrevistas com a família que integrou este estudo seguindo-se a orientação teóricometodológica do Modelo Calgary de Avaliação de Família(10), fazendo-se um recorte que se centra na avaliação estrutural deste grupo familiar. Os dados são apresentados enfatizando-se os seguintes aspectos da avaliação estrutural: estrutura interna (composição familiar, gênero, orientação sexual, ordem de nascimento, subsistemas, limites), estrutura externa (família extensa e sistemas mais amplos), contexto (etnia, raça, classe social, religião e espiritualidade, ambiente).

Para fins de sistematização o texto apresentado foi disposto conforme os seguintes sub-itens: genograma da família de Guilherme, apresentação da família de Guilherme, resumo das entrevistas, apresentação do ecomapa e descrição das relações da família de Guilherme no supra-sistema. 

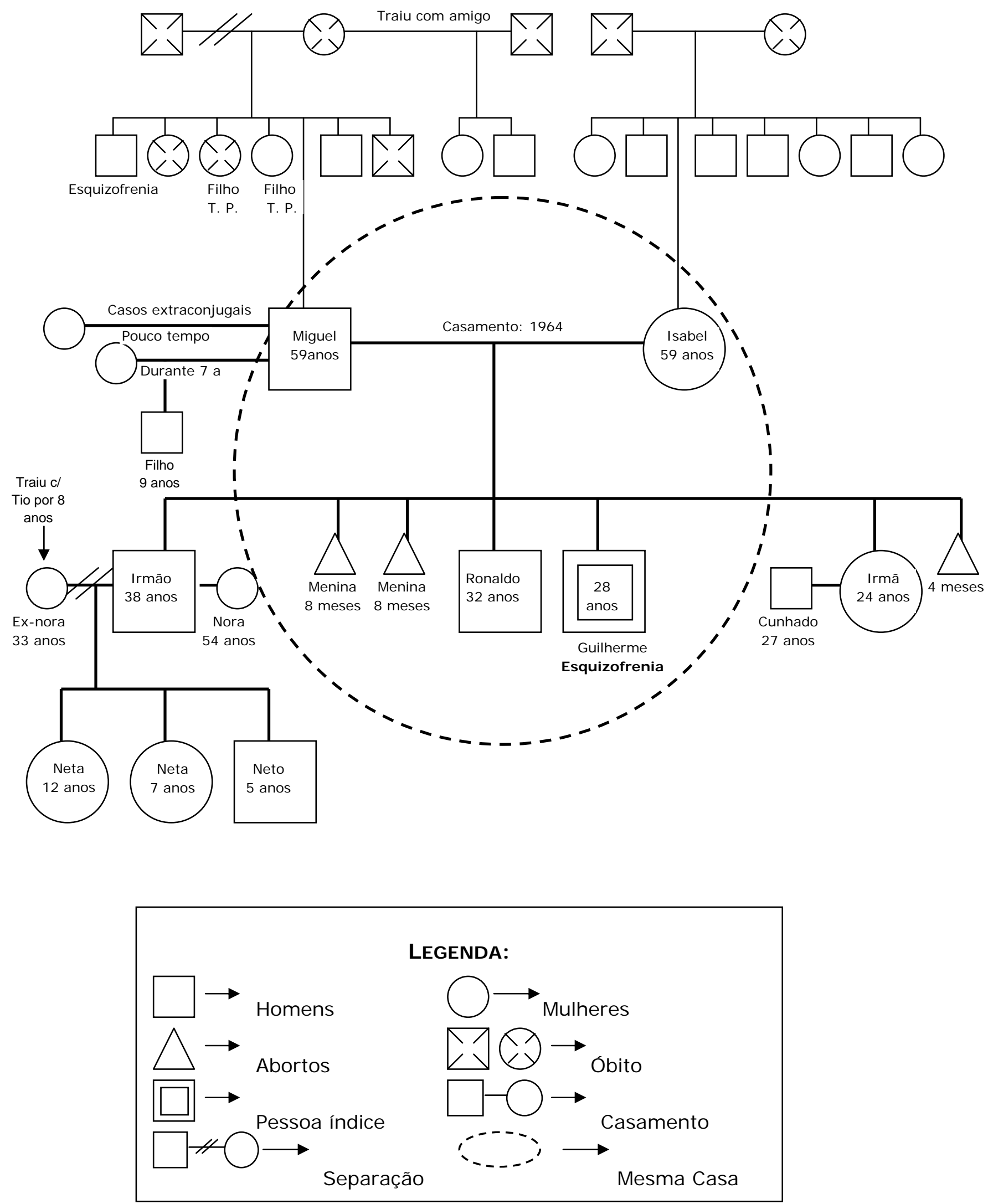

Figura 1: Genograma da família de Guilherme, Pelotas, 2004.

\section{Apresentação da família de Guilherme}

Sr. Miguel, cinqüenta e nove anos, quinto filho, teve uma infância muito difícil, possui mais oito irmãos (quatro homens - um já falecido e quatro mulheres - duas já falecidas), seis do primeiro relacionamento da mãe e mais dois do segundo.
Quando tinha dez anos, sua mãe traiu o pai com o seu melhor amigo que trabalhava no mesmo local (Corpo de Bombeiros). A partir daí, morou com seu pai, diferente dos seus demais irmãos que decidiram morar com a mãe. Seu irmão mais velho, segundo ele, começou a apresentar problemas mentais desde 
então (Esquizofrenia). Estudou até o sexto ano do ensino básico, não estudou mais porque teve que trabalhar para ajudar na renda da casa. Casou-se com Dona I sabel aos dezenove anos, enquanto servia o exército. Após cinco anos de casamento se relacionou com outra pessoa durante um curto tempo, este relacionamento extraconjugal foi descoberto pela esposa que o perdoou, mas prometeu não perdoá-lo novamente caso o fato viesse a se repetir. Acerca de quinze anos atrás se envolveu, novamente, com outra mulher num relacionamento que se estendeu por sete anos e do qual teve um filho que atualmente tem nove anos. Dona Isabel quando soube do caso do marido (a mais ou menos oito anos) disse que não o perdoaria. A relação do casal ficou gravemente prejudicada, começaram as brigas e o relacionamento ficou muito complicado. O Sr. Miguel tem como profissão o conserto de eletroeletrônicos e trabalha a trinta e cinco anos numa oficina de eletrodomésticos.

Dona Isabel, cinqüenta e nove anos, terceira filha, tem sete irmãos (quatro homens e três mulheres). Estudou até o sexto ano do ensino básico. Conheceu o Sr. Miguel quando tinha dezenove anos, tiveram o primeiro filho logo após o casamento (menos de dois anos). Quando soube que o marido a traíra se decepcionou com a relação, acreditava muito no marido, tinha-o como um homem "decente". Com o passar do tempo acabou perdoando o marido pelo fato, justificando que o relacionamento durou pouco tempo e que se tratava de uma mulher de outra cidade que estava visitando um cunhado. Mas algum tempo depois, novamente, o Sr. Miguel teve outro relacionamento extraconjugal só que desta vez Dona Isabel não o perdoou e a partir daí, começaram as agressões verbais dentro da casa.

O irmão mais velho de Guilherme tem trinta e oito anos, trabalha como jardineiro, não foi alfabetizado, mas repetiu várias vezes o primeiro ano, sem nunca ter passado deste. Segundo sua mãe, ele apresenta déficit mental, informação pouco clara já que não se obteve mais dados quanto uma possível avaliação ou testagem da inteligência, sabese que ele trabalha como jardineiro e realiza todas as atividades do serviço sem problemas. Casou-se, teve três filhos (duas meninas e um menino), mas acerca de dois anos soube que sua mulher manteve um caso extraconjugal com um tio durante oito anos e então decidiu se separar. Atualmente, vive com uma mulher mais velha que tem cinqüenta e quatro anos, em outro local, separado da mãe. As duas filhas moraram com Dona Isabel durante três anos, mas agora se encontram com a mãe. O menino teve paralisia infantil e desde o nascimento foi "adotado" pelo tio materno que não podia ter filhos.

O segundo filho do casal - Ronaldo (anteriormente, Dona Isabel já havia tido um parto prematuro de duas meninas com hidrocefalia que foram a óbito com oito meses de gravidez) tem trinta e dois anos, atualmente encontra-se desempregado, realiza trabalhos temporários e informais na construção civil. Estudou até o sexto ano do ensino básico, mora junto com os pais. É pouco comunicativo; as informações sobre ele foram dadas pela mãe e pelo pai. Ele se trata há dois anos para depressão num Centro de Atenção Psicossocial diferente do CAPS em que seu irmão Guilherme é acompanhado, isto pelo fato deste local ser perto da casa da avó (com a qual tinha um vínculo muito forte e por isto passava bastante tempo na casa desta avó).

Guilherme, terceiro filho, tem vinte e oito anos e tem Esquizofrenia. Segundo a CID-10 (Classificação Internacional de Doenças) "os transtornos esquizofrênicos se caracterizam em geral por distorções fundamentais e características do pensamento e da percepção, e por afetos inapropriados ou embotados. Usualmente mantém-se clara a consciência e a capacidade intelectual, embora certos déficits cognitivos possam evoluir no curso do tempo. Os fenômenos psicopatológicos mais importantes incluem o eco do pensamento, a imposição ou o roubo do pensamento, a divulgação do pensamento, a percepção delirante, idéias delirantes de controle, de influência ou de passividade, vozes alucinatórias que comentam ou discutem com o paciente na terceira pessoa, transtornos do pensamento e sintomas negativos"(11).

A mãe, anteriormente à descoberta da doença, relata que Guilherme "era ativo, era um rapaz normal", tocava bateria numa banda de rock e almejava o sucesso. Inúmeras vezes esta banda se apresentou pela cidade em festas e encontros musicais, mas o sucesso é para poucos. Aos vinte anos, soube do caso extraconjugal de seu pai, isto fez com que ele largasse a banda na qual tocava, e passou a ficar mais em casa, não queria nunca sair, os amigos deixaram de procurá-lo, passou a se distanciar de todos. Como o comportamento de Guilherme sempre foi de timidez, de pouca fala, os familiares não notaram nada de diferente. Quando ele passou a não se alimentar e a falar sozinho é que os familiares notaram que havia algo de errado com Guilherme. Internaram-no em um hospital psiquiátrico, mas ele ficou somente por quinze dias e foi liberado para ser acompanhado em ambulatório. Há dois anos atrás, passou a se tratar num Centro de Atenção Psicossocial que atende a região onde mora. Atualmente, faz uso de terapia medicamentosa com os seguintes antipsicóticos: semap, também conhecido como penfluridol (1 comprimido de sete em sete dias) e clorpromazina gotas ( 13 gotas duas vezes ao dia).

A irmã mais nova de Guilherme tem vinte e quatro anos, estudou até concluir o ensino médio e trabalha em um supermercado. Casou-se há quatro 
anos com um colega de trabalho que está estudando engenharia elétrica (um subsistema marido-mulher). Ela tem um relacionamento bom com os seus familiares, exceto seu pai (um subsistema pai-filha). Logo após descobrir o caso extraconjugal de seu pai, ela se revoltou muito e passou a não dialogar com o pai e evita a ida até a casa dos pais. Ela tem um carinho muito especial com seu irmão Guilherme e procura, quando pode, auxiliar sua mãe no cuidado do irmão (um subsistema irmã-irmão). Para Dona Isabel esta filha é "uma ótima pessoa, trabalhadora, tem um bom marido", sente a falta da filha em casa.

A mãe de Dona Isabel faleceu logo após nossa primeira entrevista. Quando visitamos pela primeira vez ela estava internada em um hospital devido a um enfisema pulmonar. Ela era um grande apoio para a família, segundo Sr. Miguel ela era "uma ótima pessoa, na qual todos se espelhavam". Dona Isabel também expressou o luto que estava passando no momento, relatando o quanto à mãe representava para a família. Após a morte da mãe, Dona Isabel, juntamente com as demais irmãs, cuida de um irmão que teve um Acidente Vascular Cerebral e que antes estava sob os cuidados da mãe.

A família mora em residência própria e vive com a renda do Sr. Miguel e com recursos oriundos de uma outra casa alugada, no entanto o total da renda familiar não ultrapassa três salários mínimos. O local onde a família mora é o mesmo há mais ou menos trinta e cinco anos e se encontra em um bairro na periferia da cidade.

\section{Síntese das entrevistas}

A primeira entrevista familiar aconteceu no dia trinta de junho de dois mil e quatro, quarta-feira, no horário combinado com os participantes de acordo com a conveniência dos mesmos, no domicílio de D. Isabel. Esta entrevista foi dedicada, basicamente, à construção do genograma bem como a identificação das preocupações da família em relação ao problema de saúde de Guilherme.

Dona Isabel estava um pouco agitada devido à suspeita de que sua neta de doze anos estaria grávida (gravidez não confirmada na segunda entrevista). Após acalmar-se, começou-se a coleta de informações para o genograma. Ela relatou as histórias familiares, os nomes dos parentes vivos, bem como os falecidos. A mãe de Dona Isabel estava com enfisema pulmonar e naquele momento se encontrava internada, ela preocupava-se com a saúde da mãe e com as dificuldades pelo qual estavam passando.

Nesta entrevista Dona Isabel manifestou necessidade de informações sobre o transtorno mental de seu filho Guilherme, neste momento da entrevista realizou-se um esclarecimento mais detalhado sobre o que é a doença e as demais dúvidas apresentadas por Dona Isabel. Manifestou também a necessidade de que o seu marido também se fizesse mais presente no cuidado do filho. Foi sugerido que, se possível, seu esposo pudesse estar presente para que ele pudesse nos dar mais informações acerca da família, ela disse que ele só estaria disponível nos sábados à tarde e domingo. Relatou os relacionamentos extraconjugais de seu esposo e suas conseqüências. Neste primeiro encontro já foi possível montar o genograma familiar, algumas informações, no entanto foram complementadas nas entrevistas seguintes.

A segunda entrevista familiar aconteceu no dia quatorze de julho de dois mil e quatro, quarta-feira, também no domicílio, conforme o horário combinado. Estruturar o ecomapa e discutir com maior profundidade o relacionamento familiar foram as principais atividades realizadas. Dona Isabel e os demais familiares estavam em luto devido à morte da sua mãe. Ela voltou a ressaltar a importância que a sua mãe tinha para a família.

Dona Isabel voltou a comentar o caso extraconjugal do marido, citando uma informação nova de que seu marido tem um filho. Mostrou-se muito nervosa ao comentar acerca deste filho, disse "ignorar" a existência deste, nem se quer sabia o nome do menino. Ao mesmo tempo, Dona Isabel diz que ele é "um bom marido, ele coloca as coisas para dentro de casa", explicitando que o fator financeiro é o principal motivo para o relacionamento continuar.

Quando perguntada sobre o Ronaldo, Dona Isabel demonstrou pouco conhecimento da vida do filho (subsistema mãe-filho). Ele se trata desde 2002 em um CAPS e ela só foi saber disso a pouco mais de um mês, porque uma irmã dela a informou. Ronaldo está se tratando para depressão, conversa muito pouco, quando questionado respondia o mínimo.

A falta do recebimento do benefício do INSS (Instituto Nacional de Seguridade Social) fornecido aos portadores de transtorno psíquico que recolhem contribuição previdenciária foi uma preocupação relatada pelos familiares, visto que o Sr. Miguel está quase se aposentando.

A terceira entrevista familiar aconteceu no dia trinta e um de julho de dois mil e quatro, sábado, no domicílio, conforme o horário combinado. Este foi o primeiro encontro que foi possível contar com a participação do Sr. Miguel, por isso, aproveitou-se para ouvi-lo um pouco mais.

Sr. Miguel disse que desde que se soube do transtorno psíquico de Guilherme nada mudou na família (subsistema pai-filho). Mostrou-se um pouco alienado ao que ocorre na família, e também quanto ao tratamento de Guilherme. Quando perguntado acerca dos relacionamentos extraconjugais, confirmou-os alegando que foi coisa da idade, que era muito novo. Ele tem consciência que estes relacionamentos não foram experiências positivas para a família. 
Quanto ao benefício de Guilherme, Sr. Miguel revelou que o seu patrão, atualmente está pagando o INSS para que depois de algum tempo seu filho possa se aposentar por invalidez. Isto em muito irá beneficiar a família e, de certa forma veio tranqüilizar a todos. Como sugestões dadas ao Sr. Miguel foram de que ele participasse mais ativamente no cuidado da saúde de Guilherme, inclusive do grupo de família desenvolvido no CAPS, uma vez por mês, visto que até aquele momento só Dona Isabel freqüentava.

Por meio dos dados coletados na família, foi possível montar o ecomapa familiar que está exposto a seguir. Nele é possível observar o grau de intensidade dos relacionamentos, bem como as relações extrafamiliares.
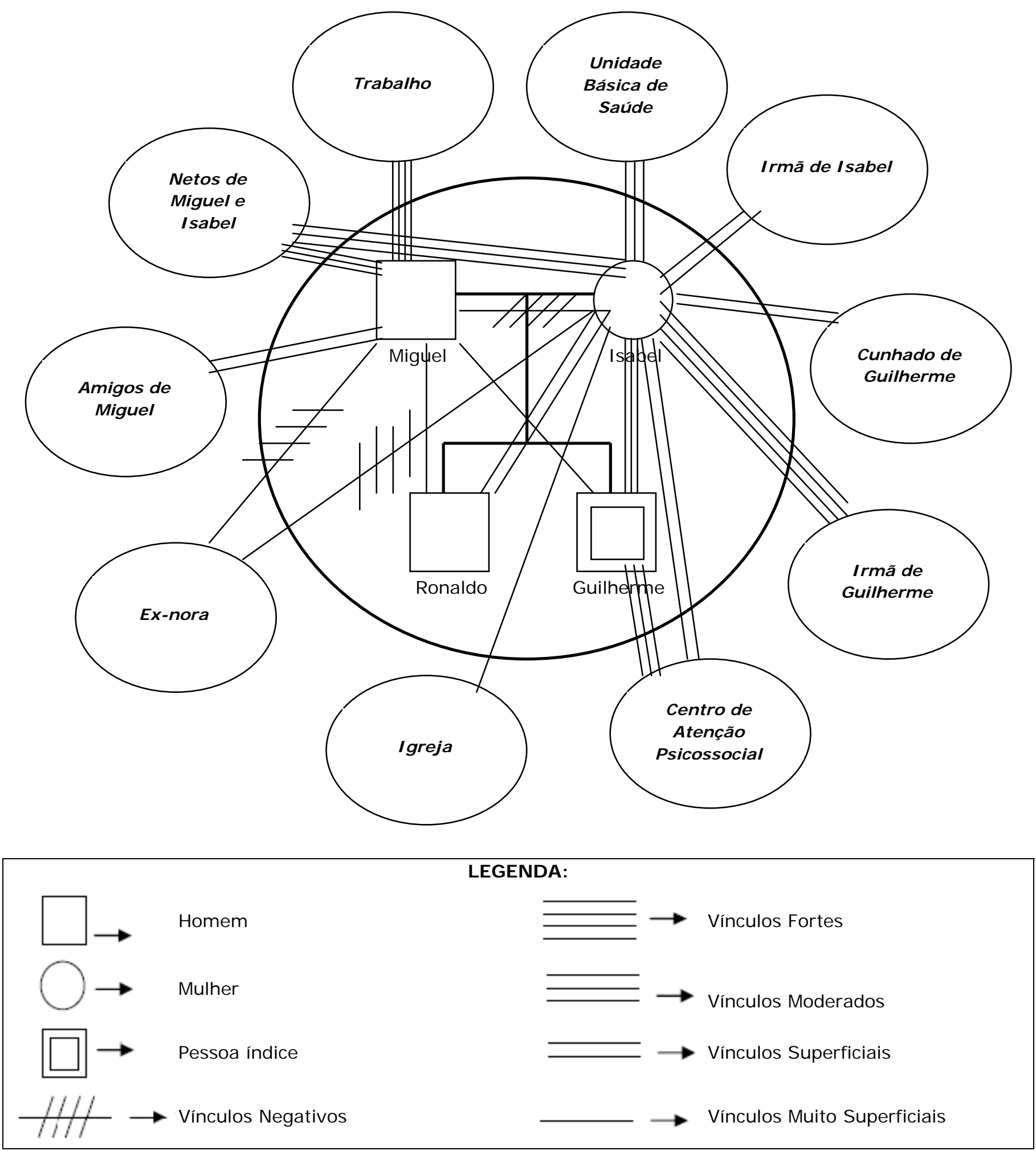

Figura 2: Ecomapa da família de Guilherme, Pelotas, 2004. 


\section{Relações da família de Guilherme no supra- sistema}

A família tem um bom relacionamento com a Unidade Básica de Saúde, quando necessário, procuram o serviço. Dona Isabel consulta com uma médica clínica, conhece os profissionais e retira mensalmente os medicamentos que necessita para hipertensão. Os filhos quando precisam também fazem uso do serviço. O mais relutante em procurar o serviço é o Sr. Miguel, ele disse que "trabalha muito" e que não tem tempo para se preocupar com a saúde, refere que quando precisar irá procurar a Unidade Básica de Saúde.

O Centro de Atenção Psicossocial (CAPS) é citado freqüentemente pelos familiares. Embora não participe como familiar no CAPS, o Sr. Miguel reconhece a melhora do filho depois que este começou a ser tratado neste local. A Dona Isabel elogia constantemente o serviço, ressaltando a importância que este teve para Guilherme.

$\mathrm{O}$ trabalho do Sr. Miguel é um local de apoio para este, seu patrão é um amigo da família e freqüentemente o ajuda. Um exemplo disso é o fato de estar pagando o INSS para o Guilherme para que no futuro ele se aposente. Os amigos fazem parte da rede social do Sr. Miguel, que está sempre com eles, ele tem o hábito de beber "uma cervejinha" todos os dias com os amigos.

Dona Isabel e Sr. Miguel (subsistema maridomulher) sentem muito a falta dos netos, eles moraram três anos junto com os avós, o que intensificou a relação netos-avós (um subsistema). A relação dos avós com a mãe das crianças é ruim, porque ela tirou as crianças da casa dos avós, e também porque ela traiu a confiança da família quando cometeu adultério durante oito anos com um tio consangüíneo.

A filha mais nova é o orgulho da família, todos gostam dela e do seu marido, mesmo assim, ela não conversa com o seu pai. Segundo a Dona Isabel ela ainda está muito magoada com o pai devido aos casos extraconjugais. Dona Isabel teve dois abortos, ambos do sexo feminino. Gosta muito da filha, refere que suas atitudes são melhores do que os demais. Relata que o melhor genro do mundo é o dela. A preferência de Dona Isabel pela filha é explicitada na presença dos demais filhos. Dona Isabel foi alertada sobre este fato e a situação foi discutida abertamente com ela.

A relação de Dona Isabel com Guilherme (subsistema mãe-filho) é de superproteção, muitas vezes, mostrou dependência e não inclusão dos irmãos e do pai no cuidado do filho, ao mesmo tempo, ela cobrava isto dos familiares. Quando questionada sobre a autonomia que o filho poderia adquirir ela concordava, mas quando foi sugerido que Guilherme fosse sozinho ao CAPS ela não realizava o combinado. Estabeleceu-se como uma hipótese sistêmica nesta família que: quanto mais a Dona Isabel assume a responsabilidade sobre o filho menos ele consegue se cuidar. Esta questão também foi trabalhada com Dona Isabel, no sentido de demonstrar os interesses de busca de autonomia de seu filho e as impossibilidades construídas no cotidiano familiar. É importante observar a questão dos limites existentes na família, quando sugerida a autonomia de Guilherme, prevaleceu o desejo inconsciente de Dona Isabel reforçando a dependência do filho.

Dona Isabel atribui à família do Sr. Miguel, a herança do transtorno psíquico de Guilherme. Observando o genograma é possível visualizar três parentes (um irmão e dois sobrinhos) do Sr. Miguel que eram portadores de transtorno psíquico. O Sr. Miguel reconhece uma relação genética com a psicopatologia do filho e acaba declarando que seu sangue é "ruim". "A esquizofrenia provavelmente compreende um grupo de transtornos com causas heterogêneas e, com certeza, abrange pacientes cujas apresentações clínicas, respostas ao tratamento e o curso da doença são variados"(12); são citados vários fatores que podem determinar a origem da doença, tais como: fatores biológicos, genéticos e psicossociais. O que é importante observar é que nenhum destes fatores isoladamente pode definir se o indivíduo terá ou não esquizofrenia. A família foi esclarecida sobre os aspectos genéticos na determinação da esquizofrenia e sobre a relação entre as diferentes determinações desta doença.

A família de Guilherme tem origem portuguesa, como a maioria do povo da cidade em que vivem. No entanto, a família pouco incorporou os costumes e hábitos de seus ascendentes. Quando questionados sobre as heranças culturais da família, informaram ter perdido estes hábitos ao longo do tempo.

Dona Isabel acredita muito em Deus, disse que tem muita fé. Diz-se católica, mas freqüenta algumas igrejas evangélicas de seu bairro. O fato de a família ter uma referência religiosa faz com que eles possam ter um apoio espiritual, Dona Isabel diz que está sempre rezando e que acreditar em Deus a ajuda a vencer as adversidades.

\section{CONSI DERAÇÕES FI NAIS}

Neste estudo foi possível avaliar estruturalmente uma família onde um portador de transtorno mental grave vive e adoeceu. Por meio da abordagem descritiva e qualitativa foi possível realizar a avaliação estrutural da família e identificar pessoas e instituições de apoio no cuidado ao indivíduo portador de transtorno psíquico e sua família.

Ressaltamos como um fato interessante nesta família estudada a questão das traições. No referencial sistêmico se busca um padrão de relacionamentos que se repetem através das gerações. O genograma é um instrumento que 
possibilita observar tais repetições. Percebemos que esta família aceita a presença da figura do pai que traiu a mãe, porém critica com freqüência esse pai. De certa forma ele está presente, mas a família insiste em excluí-lo. Este tema prevalece mais do que a própria doença mental. Observamos que em meio a sofrimentos relacionados com o transtorno mental tem o próprio contexto familiar, pois caso não houvesse uma pessoa doente talvez não ficássemos sabendo desta história de traições. Neste sentido nos questionamos se a traição não consiste no elemento de maior vulnerabilidade para este grupo. Isto nos remete para as possíveis implicações de sairmos do hospital, da sala do serviço comunitário e ganharmos à rua, a família como espaços necessários para a assistência.

Constatamos que esta família já tem alguma experiência com o transtorno mental, pois tem um tio com o mesmo diagnóstico. Então esta família pode entender a doença como algo que se explica pela genética simplesmente. O que se evidencia é que este contexto familiar é marcado por casamentos complicados pela traição, comprometendo de alguma forma a necessidade das pessoas de se sentirem seguras. Esta consideração adquire relevância quando resgatamos que uma característica de determinados quadros de transtornos mentais é exatamente a desconfiança, o jogo de omitir.

É importante ressaltar que, muitas vezes, a família sente-se limitada para cuidar do seu familiar com transtorno psíquico e encontra dificuldade de se reunir, discutir e resolver seus problemas. A elaboração do genograma e do ecomapa foram instrumentos que possibilitaram um espaço de diálogo, viabilizando a discussão de temas que jamais haviam sido verbalizados entre os membros da família estudada.

Concluímos que o presente estudo contribui para os enfermeiros que pretendem trabalhar com famílias, dispondo de um substrato teórico sistêmico, de um modelo para avaliação estrutural de famílias e de uma fundamentação para o processo de cuidado em saúde mental.

\section{REFERÊNCI AS}

1. Elsen I. Desafio da Enfermagem no cuidado de famílias. In: Elsen I. Marcos para a Prática da Enfermagem com a Família. Florianópolis: Editora da UFSC; 1994. p. 61-77.

2. Melman J. Intervenções familiares no campo da reforma psiquiátrica. In: Fernandes MI organizador. Fim do século: ainda manicômios? São Paulo: IPUSP; 1999. p. 171-86.

3. Kalil M, org. Saúde mental e cidadania no contexto dos sistemas locais de saúde. São Paulo: HUCITEC/Cooperação Italiana em Saúde; 1992.

4. Amarante P. Manicômio e loucura no final do século e do milênio. In: Fernandes MI, organizador.
Fim de século: ainda manicômios? São Paulo: IPUSP; 1999. p. 47-52.

5. Boff L. Saber cuidar: ética do humano - compaixão pela terra. Petrópolis: Vozes; 1999.

6. Schrank G, Olschowsky A. O centro de Atenção Psicossocial e as estratégias para inserção da família. Rev. esc. enferm. USP. 2008;42(1):127-34.

7. Dias J, Nascimento LC, Mendes IJM, Rocha SMM. Promoção de saúde das famílias de docentes de enfermagem: apoio, rede social e papéis na família. Texto contexto-enferm. 2007; 16(4):688-95.

8. Moura LS, Kantorski LP, Galera SAF. Avaliação e intervenção nas famílias assistidas pela equipe de saúde da família. Rev. gaúcha enferm. 2006; 27(1): 35-44.

9. Polit DF, Hungler B. Fundamentos de pesquisa em enfermagem. 3rd ed. Porto Alegre: Artes Médicas; 1995.

10. Wright L, Leahey M. Enfermeiras e famílias: um guia para avaliação e intervenção na família. 3rd ed. São Paulo: Roca; 2002.

11. Organização Mundial da Saúde. Classificação de Transtornos Mentais e de Comportamento da CID-10: Descrições Clínicas e Diretrizes Diagnósticas. Porto Alegre: Artes Médicas; 1993.

12. Kaplan HI, Sadock BJ. Compêndio de Psiquiatria. 2nd ed. Porto Alegre: Artes Médicas; 1990.

Artigo recebido em 20.12.07.

Aprovado para publicação em 31.03.09. 